Elisa Gnatta*, Martina Zaninotto, Maria Grazia Epifani, Andrea Padoan, Romelda Gjini and Mario Plebani

\title{
A new sampling device for faecal immunochemical testing: haemoglobin stability is still an open issue
}

\begin{abstract}
Background: The detection of faecal occult blood is a fundamental step in making an early diagnosis of colorectal cancer. The aim of the present study was to evaluate the stability of haemoglobin in faeces collected with two sampling devices specific for faecal immunochemical testing (FOB Gold Tube Screen and FOB Gold Tube NG) that contain different preservative buffers (buffer $\mathrm{H}, \mathrm{BH}$, and buffer N, BN, respectively).
\end{abstract}

Methods: Fifteen true positive faecal samples were collected with both devices. A pool from each sample was made. Each pool was portioned and stored at $+4^{\circ} \mathrm{C},+21^{\circ} \mathrm{C}$ and $+32^{\circ} \mathrm{C}$ for 10 days. One aliquot of each pool stored at each of the respective temperatures was tested at five time intervals between sampling and analysis. The same procedure was followed for three synthetic haemoglobin solutions in both buffers.

Results: The percentage of cumulative faecal haemoglobin decrease (HbCD\%) was evaluated. No significant difference was found between $\mathrm{BH}$ and $\mathrm{BN}$ in $\mathrm{HbCD} \%$ at $+4^{\circ} \mathrm{C}$ $(\mathrm{p}=0.106)$; at $+21^{\circ} \mathrm{C}$ and $+32^{\circ} \mathrm{C}, \mathrm{HbCD} \%$ was lower in $\mathrm{BH}$ than in BN samples ( $p=0.002$ and $p=0.001$, respectively) whereas no difference was found between samples stored in $\mathrm{BH}$ at $+4^{\circ} \mathrm{C}$ and $+21^{\circ} \mathrm{C}$. The synthetic haemoglobin degradation percentage was always $\leq 7.1 \%$ for both buffers except for BN at $+32^{\circ} \mathrm{C}$ (about $60 \%$ ).

Conclusions: Synthetic haemoglobin solutions behave differently from the true faecal samples. At $+21^{\circ} \mathrm{C}$ and $+32^{\circ} \mathrm{C} \mathrm{BH}$ preserves the haemoglobin better than $\mathrm{BN}$, independent of the haemoglobin concentration. $\mathrm{BH}$, allowing sample stability at both $+4^{\circ} \mathrm{C}$ and $+21^{\circ} \mathrm{C}$, is more suitable for screening procedures.

Keywords: colorectal cancer; faecal immunochemical test; faecal occult blood; preservative buffer.

\author{
*Corresponding author: Elisa Gnatta, Department of Laboratory \\ Medicine, University-Hospital, Via Giustiniani 2, Padua, Italy, \\ Phone: +39 04 98212801, E-mail: elisa.gnatta@sanita.padova.it \\ Martina Zaninotto, Maria Grazia Epifani, Andrea Padoan, Romelda \\ Gjini and Mario Plebani: Department of Laboratory Medicine, \\ University-Hospital, Padua, Italy
}

\section{Introduction}

Colorectal cancer (CRC), a major public health challenge in industrialised countries, is the fourth most frequent malignancy in men and the third in women, worldwide [1], and the second-most frequent cause of cancer-related death in the Western world [2]. The onset and development CRC can be insidious [3], and a body of sound evidence demonstrates that screening the asymptomatic population can reduce CRC-related mortality [4]. Owing to the long time interval between the onset of the disease and the appearance of symptoms, an improvement in prognosis can be achieved through early detection by means of screening with faecal occult blood tests (FOBTs) that, depending on the blood component detected, fall into two categories: the traditional guaiac-based FOBT (gFOBT) and the more recently developed faecal immunochemical test (FIT).

Traditional gFOBTs have reduced mortality in randomised controlled trials [5], but have major disadvantages [6]. In particular, the cut-off concentration between gFOBT negative and positive results set by the methodology recommended by the manufacturer cannot easily be adjusted by the end-users. In addition, problems related to sample collection, handling and analysis strongly affect the clinical usefulness of this approach [7], thus leading many to consider it an obsolete strategy in screening programmes [8].

The more recent FIT has several advantages over gFOBT: only one sample is usually required, the available faecal sampling device facilitates uptake, and this test is more specific in cases of lower gastrointestinal bleeding. 
Several trials have demonstrated that FIT is more satisfactory than traditional gFOBT, with greater patient compliance and a diagnostic yield of advanced neoplasia at the same or a higher specificity [9-11]. FIT, now recommended in current guidelines [4], is human haemoglobin-specific and therefore obviates any need for diet restriction; moreover, haemoglobin quantification allows the selection of a suitable cut-off concentration [12]. Some concern has been raised regarding the supposed sensitivity of FIT to delayed sample delivery, the globin component being degraded quite rapidly while the haem component degrades more slowly by processes that include the removal of iron by colonic bacteria [13-15]. Although the intact globin moiety of human haemoglobin or its early degradation products can be detected using FIT, little is known about the stability of haemoglobin in different storage conditions, although it is widely accepted that this protein is unstable in faeces, $\mathrm{a} 1^{\circ} \mathrm{C}$ increase in temperature causing a $0.7 \%$ reduction in FIT positivity. In summer the probability of detecting a cancer or an advanced adenoma in screening programmes is about $13 \%$ lower than in the winter [14]. When used in a bowel cancer screening programme, the collection device may undergo a variety of different temperature changes during the time interval between sample device loading by screening participants and its arrival in the laboratory. The aim of the present study was therefore to evaluate the stability of faecal haemoglobin at different storage temperatures and different time-intervals between sampling and analysis in human positive faecal samples collected using two different types of sampling devices. In order to mimic true operational conditions, we considered the stability of the results obtained under a range of storage temperatures that simulated those encountered in clinical practice.

\section{Materials and methods}

Two faecal sampling devices by the same manufacturer (Sentinel Diagnostics, Milan, Italy) were used: a new collection device, FOB Gold $^{\circledR}$ Tube Screen (Screen) and the "first generation" device FOB Gold $^{\circledR}$ Tube NG (NG); both were employed for the collection and preservation of faecal samples for analysis with the FIT developed by the same manufacturer. The two faecal sampling devices are identical, but use different preservative buffers. The new collection tube Screen contains $1.7 \mathrm{~mL}$ of extraction solution (buffer $\mathrm{H}, \mathrm{BH}$ ). The composition and concentration of active components in the $\mathrm{BH}$ are: BSA 0.5\%, EDTA-Na $2.01 \%$, sodium azide $<0.1 \%$ and stabilisers. The collection tube NG contains $1.7 \mathrm{~mL}$ of extraction solution (buffer $\mathrm{N}$, $\mathrm{BN})$. The composition and concentration of active components in the BN are: bovine serum albumin (BSA) $1 \%$, sodium chloride $\leq 0.9 \%$, sodium azide $<0.1 \%$ and stabilisers.
This turbidimetric method allows the quantitative determination of human haemoglobin in faeces by means of an antigen-antibody agglutination reaction between the haemoglobin contained in the sample and rabbit polyclonal anti-human haemoglobin antibodies coated on polystyrene particles. The agglutination, measured as an increase in absorbance at $570 \mathrm{~nm}$, is proportional to the quantity of human haemoglobin contained in the sample.

In order to evaluate the stability of haemoglobin, two experiments were conducted, one on faecal samples, and the other on a lyophilised powder of human haemoglobin (Sigma-Aldrich, Saint Louis, MO, USA) dissolved in both preservative buffers. A comparison was performed between the two extraction buffers (in samples and in human haemoglobin solutions).

All determinations were undertaken with automated Cobas 6000 instrumentation (Roche Diagnostics, Milan, Italy).

\section{Stability tests on faecal samples}

The Screen and NG devices pick up approximately $10 \mathrm{mg}$ of faeces, which are added to $1.7 \mathrm{~mL}$ of preservative buffers (BH and $\mathrm{BN}$, respectively). The tube is designed to fit into primary sample tubes racks on most automated clinical chemistry analysers. Fifteen freshly collected faecal samples from patients with probable inflammatory bowel disease (faecal lactoferrin $>100 \mu \mathrm{g} / \mathrm{mL}$ ) were tested using Cobas 6000 to confirm the presence of occult blood. Haemoglobin concentrations ranged from 111 to $>800 \mathrm{ng} / \mathrm{mL}$. The samples were frozen until the start of the experiment. The day before the experiment, the 15 faecal samples were placed at +2 to $+8^{\circ} \mathrm{C}$ to allow gradual thawing, after which they were placed at room temperature. Taking care to ensure good sample mixing, 12 different samplings were made using 12 different Screen devices for all faecal samples. A pool of the 12 samplings was then made in order to obtain roughly $20 \mathrm{~mL}$ for each pool. The same procedure with the same samples was followed using the NG device. The pools with haemoglobin concentrations higher than the linearity limit were diluted with the appropriate buffer. Each pool was stored overnight at +2 to $+8^{\circ} \mathrm{C}$.

The starting experiment time (time 0 ) began with the analysis, in duplicate, of each pool. The mean haemoglobin concentrations of each pool at time 0 are reported in Table 1. Each pool was distributed in 21 secondary tubes (about $1 \mathrm{~mL}$ per tube) [Eppendorf, Flex Tubes ${ }^{\circledR}$ (1.5 mL) Hamburg, Germany]. The 21 aliquots were placed in three different temperatures (seven aliquots per temperature): $+4^{\circ} \mathrm{C},+21^{\circ} \mathrm{C}$ and $+32^{\circ} \mathrm{C}$. One aliquot per pool and per temperature was analysed at five different time intervals between sampling and analysis: 1, 3, 6, 8 and 10 days. Each determination was made in duplicate. Each sample aliquot was well mixed and then brought up to room temperature before assessment.

\section{Stability test on synthetic haemoglobin solutions}

The two preservative buffers (BH and $\mathrm{BN}$ ) were supplemented with lyophilised human haemoglobin powder. Three solutions were obtained for the $\mathrm{BH}$, at a low, medium and high haemoglobin concentration. At time zero, the respective values were: 120, 326 and $648 \mathrm{ng} / \mathrm{mL}$. The same procedure was followed for BN; concentrations 
Table 1 Haemoglobin faecal concentration (Hb conc) in pools evaluated at time 0.

\begin{tabular}{|c|c|c|c|c|c|c|c|c|c|c|c|c|c|c|c|}
\hline Pool number & 1 & 2 & 3 & 4 & 5 & 6 & 7 & 8 & 9 & 10 & 11 & 12 & 13 & 14 & 15 \\
\hline $\begin{array}{l}\mathrm{Hb} \text { conc, } \mathrm{ng} / \mathrm{mL} \\
\text { Screen device } \\
\text { (Preservative buffer: } \mathrm{BH} \text { ) }\end{array}$ & 111 & 158 & 154 & 191 & 172 & 347 & 263 & 248 & 292 & 319 & 209 & 420 & 239 & 366 & 576 \\
\hline $\begin{array}{l}\mathrm{Hb} \text { conc, } \mathrm{ng} / \mathrm{mL} \\
\mathrm{NG} \text { device } \\
\text { (Preservative buffer: } \mathrm{BN} \text { ) }\end{array}$ & 155 & 148 & 171 & 157 & 203 & 320 & 266 & 345 & 378 & 285 & 281 & 366 & 316 & 418 & 619 \\
\hline
\end{tabular}

at time 0 were: 128, 298 and $557 \mathrm{ng} / \mathrm{mL}$, respectively. Following preparation and overnight storage at +2 to $+8^{\circ} \mathrm{C}$ of $20 \mathrm{~mL}$ of each solution, the haemoglobin concentration was measured establishing the time zero value. Each pool was divided into 21 aliquots (about $1 \mathrm{~mL}$ per tube), prepared and analysed as described above.

\section{Statistical analysis}

The percentage of cumulative faecal haemoglobin decrease ( $\mathrm{HbCD} \%)$ was used to evaluate the haemoglobin degradation in pool samples stored in both buffers. It was calculated by the following formula at different times $t_{i}$ :

$$
H b C D \%\left(t_{i}\right)=\frac{\sum_{n=1}^{15}\left(1-\frac{H b_{n}\left(t_{i}\right)}{H b_{n}\left(t_{0}\right)}\right)}{15} \cdot 100
$$

where $H b_{n}\left(t_{i}\right)$ is equal to the haemoglobin concentration $(\mathrm{ng} / \mathrm{mL})$ of each pool $(n)$ at time $\left(t_{i}\right) 1,3,6,8$ or 10 days; $H b_{n}\left(t_{0}\right)$ is the haemoglobin concentration $(\mathrm{ng} / \mathrm{mL})$ of each pool at time zero.

The Shapiro-Wilk test was used to assess variables for normal distributions. As the variable transformation for $\mathrm{HbCD} \%$, we evaluated the log, inverse, square root and quadratic transformation in order to choose the appropriate transformation. To evaluate overall $\mathrm{HbCD} \%$ variability over time we used the repeated measure ANOVA, by which we evaluated the two groups (BH and $\mathrm{BN}$ pools) differences and the groups differences over times (time ${ }^{\star}$ groups interactions). To evaluate the differences among temperatures and time points in samples stored in $\mathrm{BH}$, we then used a repeated measures mixed model. The marginal means of the transformed $\mathrm{HbCD} \%$ were estimated by means of the fitted model. The Kruskal-Wallis test was used to assess differences between the $\mathrm{HbCD} \%$ at 3 and 6 days. All statistical analyses were performed using Stata v 12 (StataCorp LP, TX, USA).

\section{Results}

The analytical performances of the Screen system should be summarised as: 1) the limit of quantitation (LOQ), at a coefficient of variation (CV) equal or lower than $20 \%$, was $19 \mathrm{ng} / \mathrm{mL}$; 2) the imprecision ranged from $6.5 \%$ to 9.4\% (mean concentrations: $93 \mathrm{ng} / \mathrm{mL}$ and $73 \mathrm{ng} / \mathrm{mL}$, respectively); 3) no hook effect up to $20,000 \mathrm{ng} / \mathrm{mL}$; d) no interference from haemoglobin $\mathrm{S}$ variant (concentration range: $38-406 \mathrm{ng} / \mathrm{mL}$ ), haemoglobin $\mathrm{D}$ variant (concentration range: $58-656 \mathrm{ng} / \mathrm{mL}$ ) and haemoglobin $\mathrm{A}_{1 \mathrm{c}}$ (concentration range: $55-633 \mathrm{ng} / \mathrm{mL}$ ).

\section{Stability tests on faecal samples}

The time zero haemoglobin concentrations of pools ranged from 111 to $619 \mathrm{ng} / \mathrm{mL}$ (Table 1). The slight difference between the mean haemoglobin concentrations of pools collected with the two faecal sampling devices was probably due to non-homogeneity of the faecal samples. The haemoglobin in the faecal pools behaves differently depending on the different temperatures at which they are stored. At $+4^{\circ} \mathrm{C}$ and $+21^{\circ} \mathrm{C}$, over time $\mathrm{HbCD} \%$ met the normal distribution assumption after square root transformation ( $\mathrm{p}=0.133$ and 0.059 , respectively), while at $+32^{\circ} \mathrm{C}$, over time $\mathrm{HbCD} \%$ did not meet the normal distribution assumption also after square root transformation. Therefore, we used a repeated measured ANOVA with ranktransformed $\mathrm{HbCD} \%$.

At $+4^{\circ} \mathrm{C}$, no statistically significant difference ( $\mathrm{p}=0.106$; Supplementary Data Table 1, which accompanies the article at http://www.degruyter.com/view/j/ cclm.2014.52.issue-7/issue-files/cclm.2014.52.issue-7.xml) was found between $\mathrm{BH}$ and $\mathrm{BN}$ pools for $\mathrm{HbCD} \%$ over time. At $+21^{\circ} \mathrm{C}$ and $+32^{\circ} \mathrm{C}$, a statistically significant difference was found between the $\mathrm{BH}$ and $\mathrm{BN}$ pools for $\mathrm{HbCD} \%$ $(p=0.002$ and $p=0.001$, respectively; Figure 1 , Supplementary Data Table 1)

The degradation/day percentages calculated on days 3 and 6 are reported in Table 2. In pools stored in BH for 3 days at $+4^{\circ} \mathrm{C}$, the degradation/day rate was significantly higher $(\mathrm{p}=0.004)$ than in the same pools stored in BN. At $+21^{\circ} \mathrm{C}$, the degradation/day in pools stored in $\mathrm{BH}$ was significantly lower $(\mathrm{p}<0.001)$ than that in the pools stored in BN, only when degradation was ascertained within 6 days. At $+32^{\circ} \mathrm{C}$, the degradation/day was significantly lower $(\mathrm{p}<0.001)$ in pools stored in BH on all the days considered. 

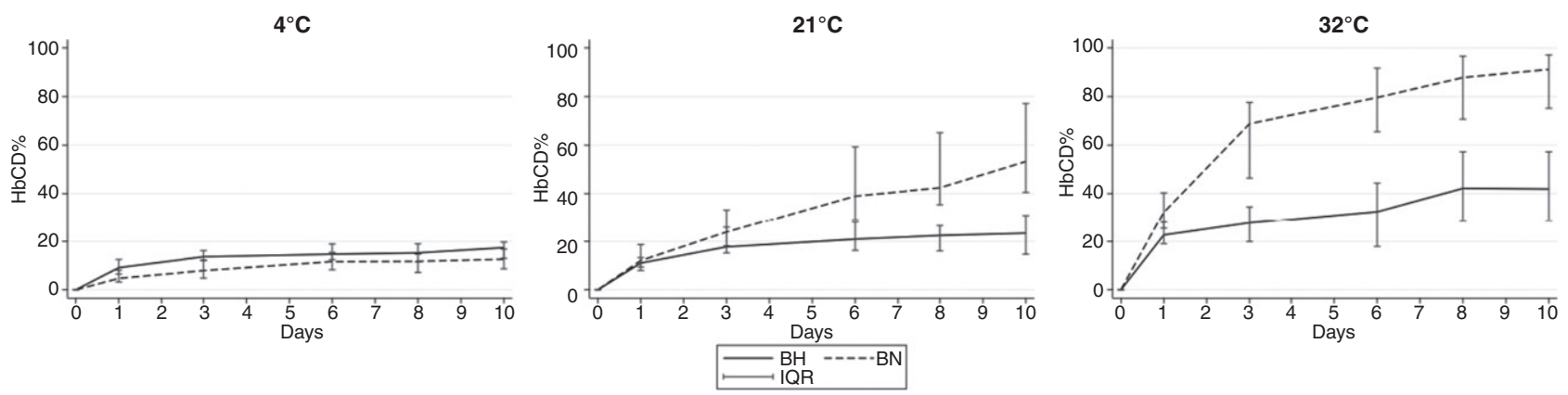

Figure 1 Haemoglobin cumulative decrease \% ( $\mathrm{HbCD} \%)$ over time calculated as the mean value on 15 faecal pools preserved in buffer $\mathrm{H}$ $(\mathrm{BH})$ and in buffer $\mathrm{N}(\mathrm{BN})$.

Table 2 Percentage of haemoglobin (\% $\mathrm{Hb})$ degradation/day.

\begin{tabular}{|c|c|c|c|c|}
\hline & $\begin{array}{l}\text { BH } \\
\text { (\% Hb degradation/day) }\end{array}$ & $\begin{array}{r}\text { BN } \\
\text { (\% Hb degradation/day) }\end{array}$ & $\begin{array}{l}\text { BH } \\
\text { (\% Hb degradation/day) }\end{array}$ & $\begin{array}{r}\text { BN } \\
\text { (\% Hb degradation/day) }\end{array}$ \\
\hline $4^{\circ} \mathrm{C}$ & & & & \\
\hline Median & 4.6 & 2.6 & 2.5 & 1.9 \\
\hline \multirow[t]{2}{*}{ IQR } & $4.1-5.9$ & $1.6-4.1$ & $2.2-3.2$ & $1.4-2.6$ \\
\hline & \multicolumn{2}{|c|}{ Kruskal-Wallis: $\chi^{2}=8.07, p=0.004^{\mathrm{a}}$} & \multicolumn{2}{|c|}{ Kruskal-Wallis: $\chi^{2}=3.52, p=0.059$} \\
\hline $21^{\circ} \mathrm{C}$ & \multicolumn{2}{|c|}{3 days } & \multicolumn{2}{|c|}{6 days } \\
\hline Median & 5.9 & 7.9 & 3.5 & 6.5 \\
\hline \multirow[t]{2}{*}{ IQR } & $5.1-8.6$ & $6.1-11.1$ & $2.7-4.7$ & $4.8-9.9$ \\
\hline & \multicolumn{2}{|c|}{ Kruskal-Wallis: $\chi^{2}=2.684, p=0.101$} & \multicolumn{2}{|c|}{ Kruskal-Wallis: $\chi^{2}=11.14, p<0.001^{a}$} \\
\hline $32^{\circ} \mathrm{C}$ & \multicolumn{2}{|c|}{3 days } & \multicolumn{2}{|c|}{6 days } \\
\hline Median & 9.2 & 22.9 & 5.4 & 13.3 \\
\hline \multirow[t]{2}{*}{ IQR } & $6.6-11.5$ & $15.5-25.8$ & $3.0-7.4$ & $10.9-15.2$ \\
\hline & \multicolumn{2}{|c|}{ Kruskal-Wallis: $\chi^{2}=16.021, p<0.001^{a}$} & \multicolumn{2}{|c|}{ Kruskal-Wallis: $\chi^{2}=17.03, p<0.001^{a}$} \\
\hline
\end{tabular}

$\% \mathrm{Hb}$ degradation/day of sample pools preserved in buffer $\mathrm{H}(\mathrm{BH})$ and buffer $\mathrm{N}(\mathrm{BN})$. a Statistically significant.

On evaluating $\mathrm{BH}$ and $\mathrm{BN}$ pools separately, the following observations were made: the samples pools stored in $\mathrm{BH}$ were divided in two groups, eight in a low $(\leq 250$ $\mathrm{ng} / \mathrm{mL})$ and seven in a high $(>250 \mathrm{ng} / \mathrm{mL})$ haemoglobin concentration. No statistically significant differences ( $p>0.05$ ) in stability were found between concentration groups at any of the three different temperatures (Figure 2, Supplementary Data Table 2). The same behaviour was also observed in pools at low (five samples) and high (10 samples) haemoglobin concentrations stored in BN, at all temperatures (Figure 2, Supplementary Data Table 2).

On evaluating the $\mathrm{BH}$ stored samples, the marginal estimated means of the square root of $\mathrm{HbCD} \%$ (Figure 3) showed no statistically significant difference between samples stored at $+4^{\circ} \mathrm{C}$ and those stored at $+21^{\circ} \mathrm{C}$ (Day 1 $\mathrm{p}=0.304$; Day $3 \mathrm{p}=0.147$; Day $6 \mathrm{p}=0.128$; Day $8 \mathrm{p}=0.084$; Day $10 \mathrm{p}=0.052$ ); the difference was significant when the samples stored at $+4^{\circ} \mathrm{C}$ were compared with those stored at $+32^{\circ} \mathrm{C}(\mathrm{p}<0.001)$.

\section{Stability tests on synthetic haemoglobin solutions}

The mean synthetic haemoglobin degradation percentage of three solutions at low, medium and high concentration was evaluated. For all conditions and times, the resulting synthetic haemoglobin degradation percentage was very low $(\leq 7.1 \%)$ for both preservative buffers (BH and $\mathrm{BN}$ ) except for the synthetic haemoglobin solution dissolved in $\mathrm{BN}$ and stored at $+32^{\circ} \mathrm{C}$; at this temperature the degradation percentage started to increase after 3 days (35.7\%), being $60 \%$ after 10 days.

\section{Discussion}

This study was conducted to evaluate the stability of haemoglobin in human faecal samples collected using a new device (Screen) in comparison to the previous generation 

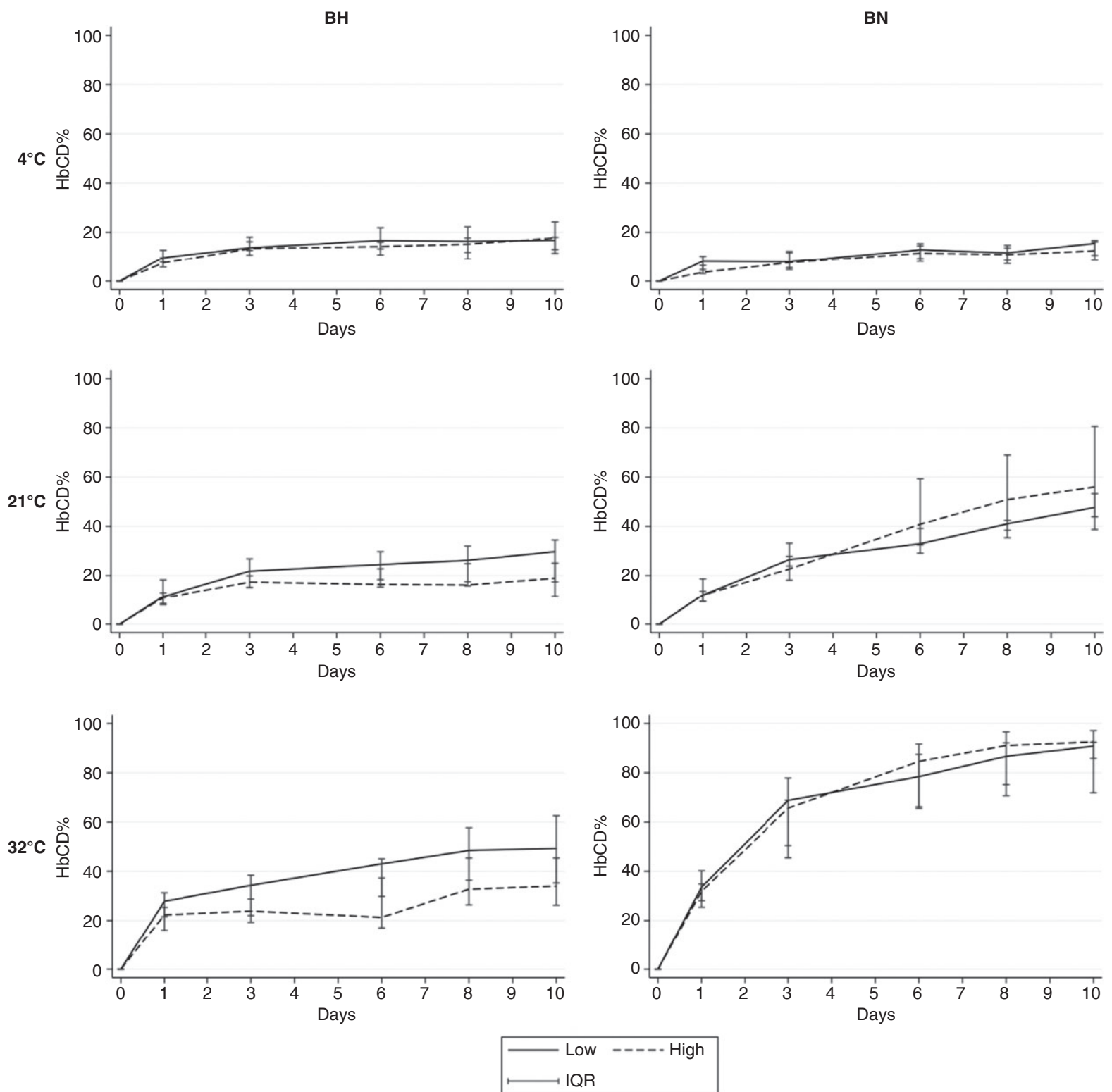

Figure 2 Haemoglobin cumulative decrease \% ( $\mathrm{HbCD} \%)$ over time according to haemoglobin concentrations: low $(\leq 250 \mathrm{ng} / \mathrm{mL}) \mathrm{and} \mathrm{high}$ $(>250 \mathrm{ng} / \mathrm{mL})$.

device (NG). The good analytical performances of the system, namely its imprecision and linearity, allowed us to reliably evaluate any significance in the observed haemoglobin variations over time.

It has been established that haemoglobin stability in faecal samples can be influenced by several factors, such as storage conditions and lag time prior to analysis [16, 17]. In particular, a delay between sampling and arrival at the laboratory can lead to false negatives due to haemoglobin degradation, especially if the sample is kept at room temperature. Moreover, a delay between faecal sampling and laboratory delivery decreases the FIT test performance, this effect being independent of the cut-off value [17]. The stability of haemoglobin decreases in the presence of microbial contamination but can be enhanced by changes in buffer $\mathrm{pH}$ and protein concentration [14]. A temperature-related haemoglobin degradation, which can be expected, may be delayed by using a buffer containing an appropriate stabilising agent. Therefore, a preservative buffer that can reduce the globin chains degradation even at room temperature, thus allowing faecal samples to be delivered to the laboratory by regular mail, may enhance patient compliance and uptake in screening programs.

In line with findings made by other authors $[14,18,19]$, the data reported in our study confirm that faecal samples are more effectively preserved in a refrigerator. The overall 


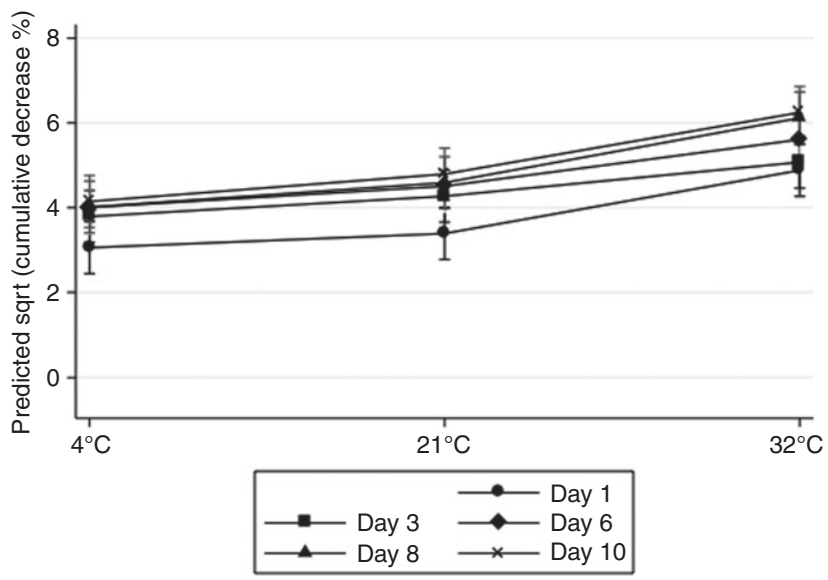

Figure 3 Mean marginal estimation of the square root of haemoglobin cumulative decrease \% in $\mathrm{BH}$ samples in relation to each temperature and each day of evaluation.

Bars represent the standard error of the mean.

difference in $\mathrm{HbCD} \%$ between the two buffers at $+4^{\circ} \mathrm{C}$ is not statistically significant (Figure 1 ) but a significant difference between $\mathrm{BH}$ and $\mathrm{BN}$ was observed following the first three days of storage (Table 2). Moreover, despite a refrigerator temperature of $+4^{\circ} \mathrm{C}$, the mean $\mathrm{HbCD} \%$ on the first day of storage was $10.2 \%$ for $\mathrm{BH}$ and $4.5 \%$ for BN (data not shown). Therefore either of the devices could yield false-negative findings in positive samples with haemoglobin values close to the cut-off after one day of storage at $+4^{\circ} \mathrm{C}$. The data reported in Table 2 may allow a calculation of the absolute decrease based on the initial haemoglobin concentration.

At $+21^{\circ} \mathrm{C}$ and $+32^{\circ} \mathrm{C}$ the two preservative buffers did not behave equally, the $\mathrm{HbCD} \%$ being more evident for $\mathrm{BN}$ over time; this difference attained statistical significance ( $p=0.002$ and $p=0.001$, respectively). However, no such statistical difference in the $\mathrm{HbCD} \%$ at room temperature was found when the sample was delivered to the laboratory within 3 days from sampling, the median degradation/day being $5.9 \%$ for $\mathrm{BH}$ vs. $7.9 \%$ for $\mathrm{BN}$ ( $\mathrm{p}=0.101$, Table 2). At a high room temperature $\left(+32^{\circ} \mathrm{C}\right)$, $\mathrm{BH}$ performed better than $\mathrm{BN}$ : the median haemoglobin degradation/ day after 3 days was 9.2 and $22.9 \%$, respectively (Table 2). As shown in Figure 3, on using BH as a preservative buffer, the $\mathrm{HbCD} \%$ of samples stored at $+4^{\circ} \mathrm{C}$ was similar to that of those stored at $+21^{\circ} \mathrm{C}$. Instead, when $\mathrm{BN}$ was used as a preservative buffer, samples had to be kept refrigerated to ensure the lowest possible $\mathrm{HbCD} \%$.

Previous studies have demonstrated that adenoma patients have lower faecal haemoglobin concentration than CRC patients [20]. This explains why haemoglobin degradation leads to high false-negative rates in a higher number of patients with minor adenomas than in those with advanced adenomas, and even fewer patients with CRC. In our study, for neither of the preservative buffers was statistically significant evidence found that $\mathrm{HbCD} \%$ depends on the sample concentration. However, at $+21^{\circ} \mathrm{C}$ and $+32^{\circ} \mathrm{C}$ in $\mathrm{BH}$ stored samples, the $\mathrm{HbCD} \%$ shows an apparently concentration-dependent trend towards degradation (Figure 2). In particular, the extent of degradation was lower in high than in low concentration samples. It is therefore likely that the increased haemoglobin degradation observed during the summer [14] will mainly affect samples from patients with small neoplastic or pre-neoplastic lesions, whose samples have haemoglobin concentrations close to the analytical cut-off value used in the screening programme.

The findings made in the present study demonstrate that faecal samples behave very differently from haemoglobin solutions: in particular, there was no degradation in any of the synthetic haemoglobin samples stored in $\mathrm{BH}$. In BN, the synthetic haemoglobin almost disappears from the solution after 10 days at $+32^{\circ} \mathrm{C}$. Therefore artificial positive samples (spiked with synthetic haemoglobin) behave differently from native positive samples thus emphasising that stability testing should always performed with real faecal samples.

Taken together, the findings made in the present study, and observations made above appear to support the view that all pre-, intra-, and post-analytical variables, including the appropriate units [21], should be taken into consideration in screening programmes using FIT.

In conclusion, the new Screen device, by allowing an improved sample stability at both $+4^{\circ} \mathrm{C}$ and at room temperature, has major advantages over the previous faecal sampling device and is more suitable for screening procedures, in which the delivery time and storage conditions are particularly complex. However, since haemoglobin degradation occurs in faecal samples as from the first day of collection, the "golden rule" must always be to deliver these samples to the laboratory as soon as possible.

\section{Conflict of interest statement}

Authors' conflict of interest disclosure: The authors stated that there are no conflicts of interest regarding the publication of this article.

Research funding: None declared.

Employment or leadership: None declared.

Honorarium: None declared.

Received December 13, 2013; accepted January 12, 2014 


\section{References}

1. Center MM, Jemal A, Smith RA, Ward E. Worldwide variations in colorectal cancer. CA Cancer J Clin 2009;59:366-78.

2. Jemal A, Siegel R, Ward E, Hao Y, Xu J, Thun MJ. Cancer statistics, 2009. CA Cancer J Clin 2009;59:225-49.

3. Cappell MS. The pathophysiology, clinical presentation, and diagnosis of colon cancer and adenomatous polyps. Med Clin North Am 2005;89:1-42.

4. Halloran SP, Launoy G, Zappa M, International Agency for Research on Cancer. European guidelines for quality assurance in colorectal screening and diagnosis. First Edition-Faecal occult blood testing. Endoscopy 2012;44(Suppl 3):SE65-87.

5. Hewitson P, Glasziou P, Watson E, Towler B, Irwig L. Cochrane systematic review of colorectal cancer screening using the fecal occult blood test (Hemoccult): an update. Am J Gastroenterol 2008;103:1541-9.

6. Fraser CG. Fecal occult blood tests. Life savers or outdated colorectal screening tools? Clin Lab News 2011;37:8-10.

7. Logan RF, Patnick J, Nickerson C, Coleman L, Rutter MD, von Wagner C, English Bowel Cancer Screening Evaluation Committee. Outcomes of the Bowel Cancer Screening Programme (BCSP) in England after the first 1 million tests. Gut 2012;61:1439-46.

8. Young GP, Fraser CG, Halloran SP, Cole S. Guaiac-based faecal occult blood testing for colorectal cancer screening - an obsolete strategy? Gut 2012;6:959-60.

9. Hol L, van Leerdam ME, van Ballegooijen M, van Vuuren AJ, van Dekken $\mathrm{H}$, Reijerink JC, et al. Screening for colorectal cancer: randomised trial comparing guaiac-based and immunochemical faecal occult blood testing and flexible sigmoidoscopy. Gut 2010;59:62-8.

10. Van Rossum LG, van Rijn AF, Laheij RJ, van Oijen MG, Fockens P, van Krieken HH, et al. Random comparison of guaiac and immunochemical fecal occult blood tests for colorectal cancer in a screening population. Gastroenterology 2008;135:82-90.

11. Park DI, Ryu S, Kim YH, Lee SH, Lee CK, Eun CS, et al. Comparison of guaiac-based and quantitative immunochemical fecal occult blood testing in a population at average risk undergoing colorectal cancer screening. Am J Gastroenterol 2010;105:2017-25.

12. Fraser $\mathrm{CG}$. A future for faecal haemoglobin measurements in the medical laboratory. Ann Clin Biochem 2012;49:518-26.

13. Brown LF, Fraser CG. Effect of delay in sampling on haemoglobin determined by faecal immunochemical tests. Ann Clin Biochem 2008;45:604-5.

14. Grazzini G, Ventura L, Zappa M, Ciatto S, Confortini M, Rapi S, et al. Influence of seasonal variations in ambient temperatures on performance of immunochemical faecal occult blood test for colorectal cancer screening: observational study from the Florence district. Gut 2010;59:1511-5.

15. Young GP, Sinatra MA, St John DJ. Influence of delay in stool sampling on fecal occult blood test sensitivity. Clin Chem 1996;42:1107-8.

16. Fraser CG, Halloran SP, Allison JE, Young GP. Making colorectal cancer screening FITTER for purpose with quantitative faecal immunochemical tests for haemoglobin (FIT). Clin Chem Lab Med 2013;20:1-3.

17. Van Rossum LG, van Rijn AF, van Oijen MG, Fockens P, Laheij RJ, Verbeek AL, et al. False negative fecal occult blood tests due to delayed sample return in colorectal cancer screening. Int J Cancer 2009;125:746-50.

18. Lee CS, O’Gorman P, Walsh P, Qasim A, McNamara D, O'Morain, et al. Immunochemical faecal occult blood tests have superior stability and analytical performance characteristics over guaiac-based tests in a controlled in vitro study. J Clin Pathol 2011;64:524-8.

19. Guittet L, Guillaume E, Levillain R, Beley P, Tichet J, Lantieri $\mathrm{O}$, et al. Analytical comparison of three quantitative immunochemical fecal occult blood tests for colorectal cancer screening. Cancer Epidemiol Biomarkers Prev 2011;20:1492-501.

20. Levi Z, Rozen P, Hazazi R, Vilkin A, Waked A, Maoz E, et al. A quantitative immunochemical fecal occult blood test for colorectal neoplasia. Ann Intern Med 2007;146:244-55.

21. Fraser CG, Allison JE, Halloran SP, Young GP. A proposal to standardize reporting units for fecal immunochemical tests for haemoglobin. J Natl Cancer Inst 2012;104:810-4. 